UCRL-JC-130980

PREPRINT

\title{
Prospects for Fluorescence Based Imaging/Visualization of Hydrodynamic Systems on the National Ignition Facility
}

\author{
L. J. Suter, O. L. Landen, J. I. Koch, D. Cohen
}

This paper was prepared for submittal to the 12th Topical Conference on High-Temperature Plasma Diagnostics Princeton, NJ

June 7-11, 1998

June 4,1998

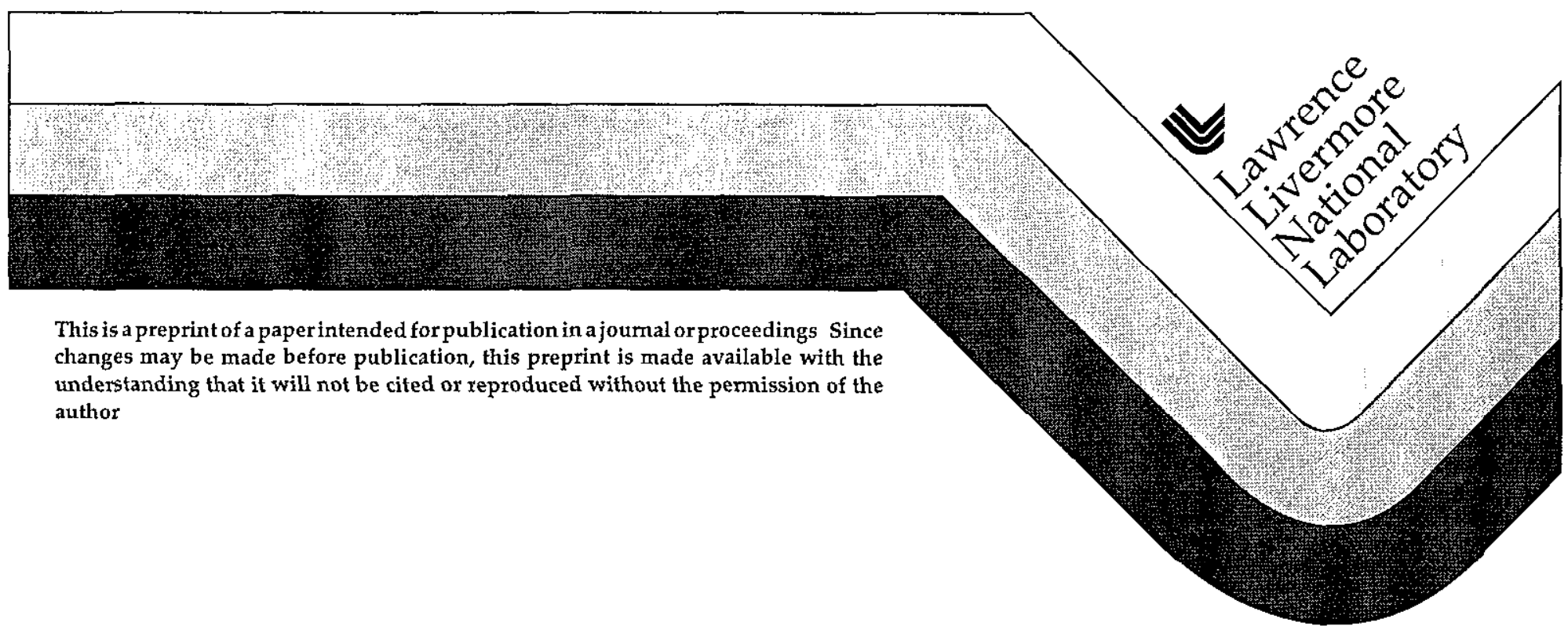




\section{DISCLAIMER}

This document was prepared as an account of work sponsored by an agency of the United States Government. Neither the United States Government nor the University of California nor any of their employees, makes any warranty, express or implied, or assumes any legal liability or responsibility for the accuracy, completeness, or usefulness of any information, apparatus, product, or process

disclosed, or represents that its use would not infringe privately owned rights. Reference herein to any specific commercial product, process, or service by trade name, trademark, manufacturer, or otherwise, does not necessarily constitute or imply its endorsement, recommendation, or favoring by the United States Government or the University of California. The views and opinions of authors expressed herein do not necessarily state or reflect those of the United States Government or the University of California, and shall not be used for advertising or product endorsement purposes. 


\section{Prospects for fluorescence based imaging/visualization of hydrodynamic systems on the National Ignition Facility}

L J Suter, O L Landen, J I Koch

Lawrence Livermore National Laboratory, Livermore, California 94551

D Cohen

University of Wisconsin, Madison, Wisconsin

The next generation of large, high power lasers, such as the National Ignition Facility (NIF) [1] in the United States, Laser Mega Joule [2] in France or Helen Successor [3] in the United Kingdom offer the prospect of $\mathrm{x}$-ray fluorescence based diagnosis of hydrodynamic experiments The $\mathrm{x}$-ray fluorescence could be pumped by at least two techniques One technique is to use a sizable fraction of these facilities' high power to efficiently make multi-kilovolt $x$-rays which, in turn, causes dopants placed in experimental packages to fluoresce We call this "externally pumped $\mathrm{x}$-ray fluorescence" The second technique is to use the sizable multi-kilovolt photon background that we expect to be present in many hohlraum based experiments, while the driving laser is on, to pump x-ray fluorescence The fluorescing medium could be a dopant in an experimental package or, possibly, a relatively thick slab of material in the hohlraum wall which could serve as a backlighter We call this "hohlraum hot-corona pumped fluorescence".

\section{Externally pumped $x$-ray fluorescence}

Extensive modeling and theory [4] supported by ongoing Nova experiments $[5,4,6]$, indicate that lasers such as NIF will be able to make multi-kilovolt x-rays with unprecedented efficiency. Figure 1 shows projected conversion efficiency of laser energy into multi-keV photons for a few types of "underdense radiators" The theoretical NIF efficiencies shown in the figure came from numerical simulations using the Lasnex computer code The multi-kilovolt sources assumed in the modeling were cylindrical berryllium containers $2 \mathrm{~mm}$ in diameter, $16 \mathrm{~mm}$ long, filled with $0.01 \mathrm{~g} / \mathrm{cc}$ of the indicated material and irradiated at 60TW The physical basis for this significant improvement in efficiency over "traditional discs" (also shown) has been previously discussed [4,5]

The high efficiencies shown in figure 1, coupled with the inherently large energy of a NIF class laser $(2 \mathrm{MJ})$ means that $100^{\prime}$ 's of kilojoules of multi-keV $\mathrm{x}$-rays could be available for applications [4] One of these applications is the pumping of fluorescent dopants strategically placed in experimental packages such as those used in the study of hydrodynamic instabilities. Of particular interest is the possibility of using fluorescence based diagnosis to visualize a slice through an experimental package, providing an image which might be very similar to contour plots produced by numerical simulations Figure 2 shows two approaches for producing such images. One, somewhat familiar technique is to dope only a region of width $\ell$ inside the target with fluorescent dopant. Conceptually, this is identical to backlighting based approaches for producing sliced images However, it has the possible advantage of working for systems with $\rho \ell \mathrm{K}<<1$, as we shall discuss below. Like backlighting based approaches, it has the disadvantage of making the experimental packages rather costly and difficult to fabricate The second technique for producing a sliceimage is schematically shown in figure $2 \mathrm{~b}$ It uses a highly collimated source to pump only a relatively thin slice of a target which may be uniformly doped This is analogous to optical fluorescence visualization of hydrodynamics experiments pumped by sheets of laser light. 
For the two types of slice imaging, the number of fluorescent photons per resolution element that would be collected by a detector of solid angle $\Delta \Omega$ is approximately given by

$$
\# \gamma_{s}^{\prime}=\frac{\eta_{>} P_{L}}{4 \pi d^{2}} w \cdot h \frac{K_{2} \rho l}{E_{>}} \frac{\eta_{f}}{4 \pi} \delta \tau \cdot \Delta \Omega \cdot\left\{\begin{array}{l}
1 \\
l / D_{\text {source }}
\end{array}\right.
$$

where $\eta_{x}$ is multi-keV source efficiency, $P_{L}$ is the laser power driving the source located distance $\mathrm{d}$ away from the physics package, $\mathrm{w}$ and $\mathrm{h}$ are the resolution width and height seen by the imaging camera, $\ell$ is the length of the doped/pumped region, $\mathrm{K}$ is the opacity of the material at the pump energy $\mathrm{E}_{>}$(which is above the $\mathrm{K}$-shell edge), $\rho$ is the dopant density, $\eta_{\mathrm{f}}$ is the probability a $\mathrm{K}$-shell vacancy will fluoresce into a given line, and $\delta \tau$ is the temporal resolution For the collimated source we assume that only a fraction of the multi-keV source power, given by $\ell \mathrm{D}_{\text {source}}$, actually pumps the desired slice where $\mathrm{D}_{\text {source }}$ is the source diameter The table summarizes $\mathrm{K}_{\mathrm{E}}$ (opacity at the $\mathrm{K}$-edge), $\eta_{\mathrm{f}}$ and $\mathrm{E}_{>\min }[7]$ for possibly important dopants

$\begin{array}{lllc}\text { Material } & \mathrm{K}_{\mathrm{E}} & \mathrm{E}_{>\min } & \eta_{\mathrm{f}} \\ \mathrm{Cl} & 1700 \mathrm{~cm}^{2} / \mathrm{g} & 29 \mathrm{keV} & 02 \\ \mathrm{Fe} & 400 & 7 & 17 \\ \mathrm{Cu} & 300 & 10 & 25\end{array}$

Using expression 1, typical numbers for a NIF experiment look promising Consider a $2 \mathrm{~mm}$ diameter $\mathrm{Ge}$ source of $10 \%$ efficiency pumped by $100 \mathrm{TW}$ located $05 \mathrm{~cm}$ from a package doped with $02 \mathrm{~g} / \mathrm{cc}$ of $\mathrm{Cu}$ If we try to take a slice with $\measuredangle=50$ microns, spatial resolution $\mathrm{w}=\mathrm{h}=10$ microns and time resolution of $100 \mathrm{ps}$, then the number of photons per resolution element going at the imaging system will be

Slice via dopant location $1.2 \mathrm{e} 9 /(10 \mathrm{micron})^{2} / 100 \mathrm{ps} / \mathrm{sr}$

Slice via collimated source: $3 \mathrm{e} 7 /(10 \mathrm{micron})^{2} / 100 \mathrm{ps} / \mathrm{sr}$

Note that it my be possible to significantly increase the collimated number by re-optimizing sources for collimated output power, probably at the expense of total energy output.

Fluorescent slice imaging might prove to be particularly useful for peering into rotationally symmetric, or even 3D, objects such as turbulent hydrodynamics experiments However, in any experiment we need be concerned about background emission overwhelming the fluorescent signal. Two source of background we have considered are thermal emission and fluorescence pumped by a hohlraum's hot-corona emission

Background thermal emission because the physics package is heated to a temperature $\mathrm{Te}$ has a Planckian limit given by

$$
\frac{\# \gamma_{s}^{\prime}}{c m^{2}}=\frac{5 \times 10^{15} \varepsilon_{\mathrm{kv}}^{3} \Delta \varepsilon_{\mathrm{kev}} \delta \tau \Delta \Omega}{\left(e^{\varepsilon / \tau}-1\right) \cdot \varepsilon_{\mathrm{kev}} \cdot 1.6 \times 10^{-16}}
$$


For the $\mathrm{Cu}$ doped example above, the number of thermal photons $/(10 \mu \mathrm{m})^{2} / 100 \mathrm{ps} / \mathrm{sr}$ collected by an imaging instrument of bandwidth $\Delta \mathrm{E}$ would be

$\mathrm{T} \quad \# /$ iesolution element

$200 \mathrm{eV} \quad 085 \Delta \mathrm{E}$

$300 \mathrm{eV} \quad 52 \mathrm{e} 5 \Delta \mathrm{E}$

both of which, for any reasonable bandwidth, are much less than the $12 \mathrm{e} 9$ and $29 \mathrm{e} 7$ from the slice example Thus background thermal emission from the experimental package does not appear to be an obvious problem if it is kept below, say, $300 \mathrm{eV}$.

Pumping of the fluorescent dopant by hohlraum hot-corona emission while the laser is on does prove to be a major source of background and will limit the utility of slice imaging via a collimated source For example, figure 3 shows our estimate, from a 2D Lasnex simulation, of the average radiation energy density inside a typical scale 10 Nova hohlraum at $1 \mathrm{~ns}, \operatorname{Tr} \sim 230 \mathrm{eV}$ We observe that the multi-keV radiation energy density is hugely greater than the radiation energy density of the equivalent Planckian The number of detected fluorescent photons produced by this radiation field is approximately given by

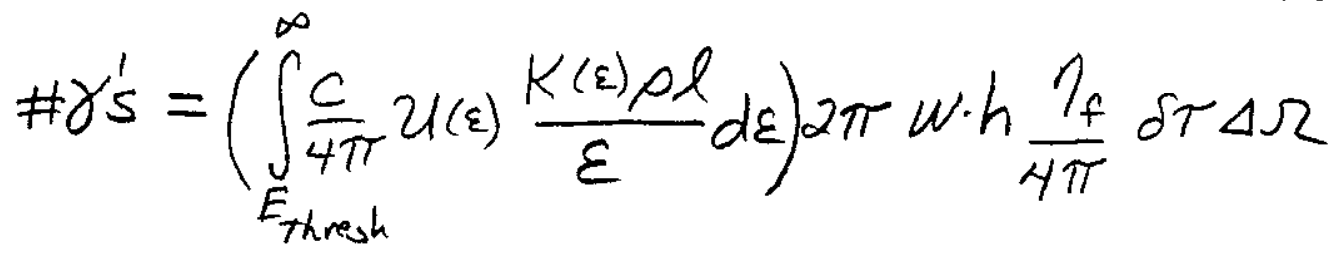

Where $E_{\text {trresh }}$ is the energy of the $\mathrm{K}$-shell edge of the dopant, $c$ is the speed of light and $u(E)$ is the energy density per $\mathrm{keV}$ of the radiation field For the $\mathrm{Cu}$ example we have been considering, the number of hot-corona pumped fluorescent photons/sr from the $10 \times 10 \times 50$ micron $\mathrm{x} 100 \mathrm{ps}$ resolution element would be

For a 50micron wide doped region $2 \mathrm{e} 9 / \mathrm{sr}$

For a 500 micron wide doped region $2 \mathrm{e} 10 / \mathrm{sr}$

Thus, hot-corona emission pumped fluorescence would be comparable to the externally pumped signal ( $2 \mathrm{e} 9 / \mathrm{sr})$ if we formed the slice by spatially localized doping and it would be $>>$ than the externally pumped signal (29e7/sr) if we formed the slice with a collimated source pumping a uniformly doped experimental package Our simulations indicate that it will take somewhat more than a nanosecond after the laser turns off for the hot-corona emission to drop to the point where collimated slice imaging would work

\section{Discussion of externally pumped $x$-ray fluorescence}

We believe that externally pumped fluorescence my have a diagnostics niche It may be useful for directly driven experiments with negligible hot-corona background and for hohlraum based hydrodynamics experiments long after the drive laser is off. In these regimes the technique has the potential to provide images approximately equivalent to contour plots of material density (and, possibly, temperature by taking advantage of temperature induced spectral shifts However, here we only consider cold fluorescence) A fundamental limitation for hohlraums will be background fluorescence pumped by hot corona emission while the hohraum drive laser is on However, as we discuss in the next section, we may be able to capitalize on this for diagnostic purposes.

\section{Hohlraum hot-corona pumped x-ray fluorescence}


Pumping of fluorescence by hot corona may have diagnostic applications not only on NIF class lasers, but it might also have some utility on current lasers such as Omega [8] and Nova We might use hot-corona emission to pump dopants placed in targets or to pump a slab of cold material in the hohlraum wall to provide a form of self-backlighting Coupled with highly tuned, narrow band imaging systems [9], this might provide a way to provide relatively high photon energy backlighting in hohlraums Our calculations indicate that very bright sources are possible, especially with higher energy density hohlraums Figure 4 shows our estimates of radiation energy density near the center of a $280 \mathrm{eV}$ and $395 \mathrm{eV}$ Nova hohlraum Also shown is opacity (/100) of cold Mo, which has a K-line at $174 \mathrm{keV}$ with a fluorescence yield of $47 \%$ Using equation (2) above, we find the number of $174 \mathrm{keV}$ photons from each $10 \times 10 \times 50$ micron $\times 100 \mathrm{ps}$ resolution element of molybdenum at density $02 \mathrm{~g} / \mathrm{cc}$ (i e $\rho_{\mathrm{M}} 0=0001$ ) to be $24 \mathrm{e} 7$ photons/sr in the $280 \mathrm{eV}$ hohlraum and $38 \mathrm{e} 8$ photons/sr in the $395 \mathrm{eV}$ hohlraum Again, it is worth noting this technique may render diagnosable a dopant layer which is optically thin, Kpl 0 01 to 01 on either side of the K-edge

For a thick "backlighting" slab, possibly behind some thin layer of wall material, the approximate expression for the number of fluorescent photons collected by an imaging detector is

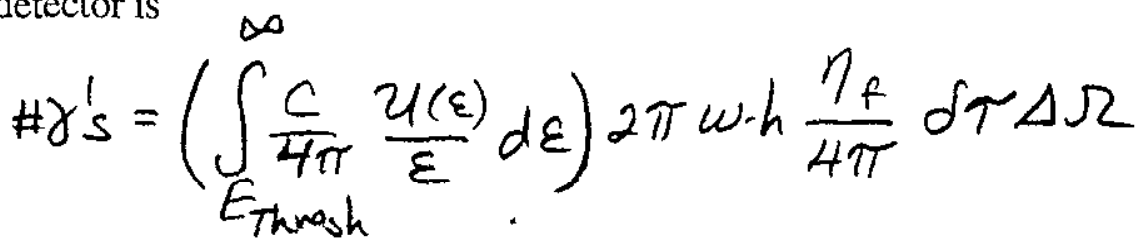

For Mo at $174 \mathrm{keV}$, the number of "backlighter" photons per 10x10micron x 100ps resolution element would be $5 \mathrm{e} 8$ photons/sr/resolution element in the $280 \mathrm{eV}$ hohlraum and $7 \mathrm{e} 9$ photons/st/resolution element in the $395 \mathrm{eV}$ hohlraum. Hohlraum hot corona pumped fluorescence may be a way of providing almost "free" diagnostic photons up to many 10's of $\mathrm{keV}$ in high energy density hohlraums. The table below lists the number of photons $/ \mathrm{sr} /(10 \mu \mathrm{m})^{2} / 100 \mathrm{ps}$ for a variety of materials pumped by the radiation field estimated for a $395 \mathrm{eV}$ Nova hohlraum.

$\begin{array}{llll}\text { Material } & \text { photon energy } & \text { thick slab } & \rho \ell=0.001 \\ \mathrm{Cu} & 8 \mathrm{keV} & 1 \mathrm{e} 11 & 2 \mathrm{e} 10 \\ \mathrm{Kr} & 13 & 2 \mathrm{e} 10 & 1.5 \mathrm{e} 9 \\ \mathrm{Mo} & 17.4 & 9 \mathrm{e} 9 & 4 \mathrm{e} 8 \\ \mathrm{Nd} & 35 & 6 \mathrm{e} 8 & 9 \mathrm{e} 6\end{array}$

For hot-corona $\mathrm{x}$-ray fluorescence to be a useful diagnostic this emission needs to be much greater than the hohlraum background emission along the diagnostic line of sight We believe this will be true for two reasons. First, within our simulations, the typical midplane line of sight passes through a much cooler region of the hohlraum For example, simulations indicate that in the $395 \mathrm{eV}$ hohlraum the $174 \mathrm{keV}$ emission along the midplane line of sight is nearly five orders of magnitude less than the emission near the LEH where virtually all the hot corona emission is created. The background $17.4 \mathrm{keV}$ emission at the midplane is equivalent to $4 \mathrm{e} 5$ photons $/ \mathrm{sr} / \mathrm{keV} /\left((10 \mu \mathrm{m})^{2} / 100 \mathrm{ps}\right.$; quite a bit lower than the estimated fluorescent signal for any reasonable bandwidth However, even if the imaging were to include the hot-corona emission it is possible that a properly tuned very narrow bandwidth detector would see mostly fluorescence signal This is because the nature of fluorescence is to integrate pump radiation over a fairly wide bandwidth but emit over a 
very narrow bandwidth For cold fluot escence, the natural linewidth ranges between $17 \mathrm{eV}$ for $\mathrm{Cu}, 6 \mathrm{eV}$ for $\mathrm{Mo}$ and $20 \mathrm{eV}$ for $\mathrm{Nd}$ Figure 5 plots fluorescent line intensities per keV for the $395 \mathrm{eV}$ hohlraum It shows the lines, especially for the thick slabs, to be significantly brighter $/ \mathrm{keV}$ than the average radiation field pumping the fluorescence It also indicates that these lines are $\sim 1 / 1000$ of the planckian limit determined by the temperature that characterizes the slope of the pumping spectrum between 8 and $20 \mathrm{keV}$

A concern we have investigated for the thick slab is whether L-shell vacancies on the surface of the slab, which are also pumped by the hot-corona, will resonantly reabsorb $\mathrm{K}$ shell fluorescence from deeper inside the slab We find that by shielding the slab to eliminate pumping by photons $<4 \mathrm{keV}$, the probability that a $\mathrm{K}$-shell photon will be resonantly reabsorbed is $<\sim 1 \%$ for both $\mathrm{Cu}$ and $\mathrm{Mo}$ when pumped by the $395 \mathrm{eV}$ hotcorona spectrum Consequently, the fluorescent intensities shown in figure 5 should be approximately correct

\section{Discussion of hohlraum hot-corona pumped $x$-ray fluorescence}

Pumping of fluorescence by hohlraum emission has already been seen on Nova and the level was about as expected Phillion [10] used $\mathrm{CH}$ slabs doped with $\mathrm{Cl}$ and $\mathrm{Na}$, placed over a hole on the side of a scale 10 Nova hohlraum, to gather a second-opinion of gold $\mathrm{M}$-band preheat inside a Nova hohlraum The fluorescent $\mathrm{Cl}$ and $\mathrm{Na}$ lines were measured with a time integrating, crystal spectrometer The fluorescent yield proved to be consistent with viewfactor estimates of hohlraum M-band levels made by combining estimates of laser spot M-band emission (as seen on disc experiments) and wall M-band emission (as measured by dante on the hohlraum midplane $[11,12]$ )

A highly tuned, spherical crystal imager $[9,13,14]$ might be a particularly good instrument to use for imaging hot-corona pumped $\mathrm{x}$-ray fluorescence With a spectral resolution $\Delta \mathrm{E} / \mathrm{E}$ $\sim 1 \mathrm{e}-5$ and a collection solid angle $\Delta \Omega \sim 1 \mathrm{e}-5$ to $1 \mathrm{e}-3$, such an instrument could collect a large number of photons per $10 \times 10 \mu \mathrm{m} \times 100 \mathrm{ps}$ resolution element. For thick fluorescers pumped by the $395 \mathrm{eV}$ hot-corona, we would expect to gather $5 \mathrm{e} 4$ to $5 \mathrm{e} 6 \mathrm{Cu} \mathrm{K}$-alpha photons (per resolution element) at $8 \mathrm{keV}, 2 \mathrm{e} 3$ to $2 \mathrm{e} 5 \mathrm{Mo} \mathrm{K}$-alpha photons at $174 \mathrm{keV}, 90$ to $9 \mathrm{e} 3 \mathrm{Nd} \mathrm{K}$-alpha photons at $34 \mathrm{keV}$

\section{Acknowledgements}

We would like to acknowledge useful discussions with Hans Griem and Max Tabak This work was performed under the auspicies of the US Department of Energy by the Lawrence Livermore National Laboratory under Contract No W-7405-ENG-48

1- J T Hunt, K. R Manes, J R Murray, P A Renard, R. W Sawicki, J B. Trenholme, and W. Williams, "A Design Basis for the National Ignition Facility," Lawrence Livermore National Laboratory, Livermore, CA, UCRL-JC-117399 (1994)

2- M. Andrè, M. Novaro, D Schirmann, "Technologie pour un Laser Megajoule", Chocs, Review Scientifique et technique de la Direction des applications militaires, Numèro 13, 73, Avril 1995.

3- J MacMordie, private communication (AWE, Aldermaston, UK, 1995)

4- L. J Suter, R L Kauffman, J. F Davis, M S Maxon, Efficient Production and Applications of 2 to $10-\mathrm{keV}$ X-rays by Laser Heated "Underdense Radiators", ICF Quarterly Report, April-June 1996, Volume 6, Number 3, Lawrence Livermore National Laboratory, UCRL-LR-105821-96-3 (1996) 
5- R L Kauffman, L J Sutet, H N Kornblum, D S Montgomery, "X-ray Production in Laser-Heated Xe Gas Targets", ICF Quarterly Report, April-June 1996, Volume 6, Number 3, Lawrence Livermore National Laboratory, UCRL-LR-105821-96-3 (1996) 6- C A Back, J Grun, C Decker, L J Suter, to be published 7- S T Perkins, D E Cullen, M H Chen, J H Hubbel, J Rathkopf, J Scofield, Tables and Graphs of Atomic Subshell and Relaxation Data Derived from the LLNL

Evaluated Atomic Data Library (EADL), $z=1-100$, UCRL-50400 Vol 30, October 31, 1991

8- J M Soures, et al, Phys Plasmas 3, 2108 (1996)

9- J Koch, Journal of Applied Optics, April, 1998

10- D Phillion, LLNL, private communication 1987

11- H N Kornblum and R L Kauffman, Rev Sci Instrum 57, 2179 (1986)

12- R L Kauffman, L J Suter, C B Darrow, J D Kilkenny, H N Kornblum, et al, Phys Rev Lett 73, 2320 (1994)

13-F J Marshall, J Ortel, A Framed Monochromatic X-Ray Microscope for ICF, Rev Sci Instrum Vol 68, No 1, 735 (1997)

14- S A. Pikuz, T. A Shelkovenko, V M Romanova, D. A. Hammer, A Ya Faenov, V M Dyakin, and T A Pikuz, High-Luminosity Monochromatic X-Ray Backlighting Using Incoherent Plasma Source to Study Extremely Dense Plasma, Rev Sci Instrum Vol 68, No 1, 740 (1997) 


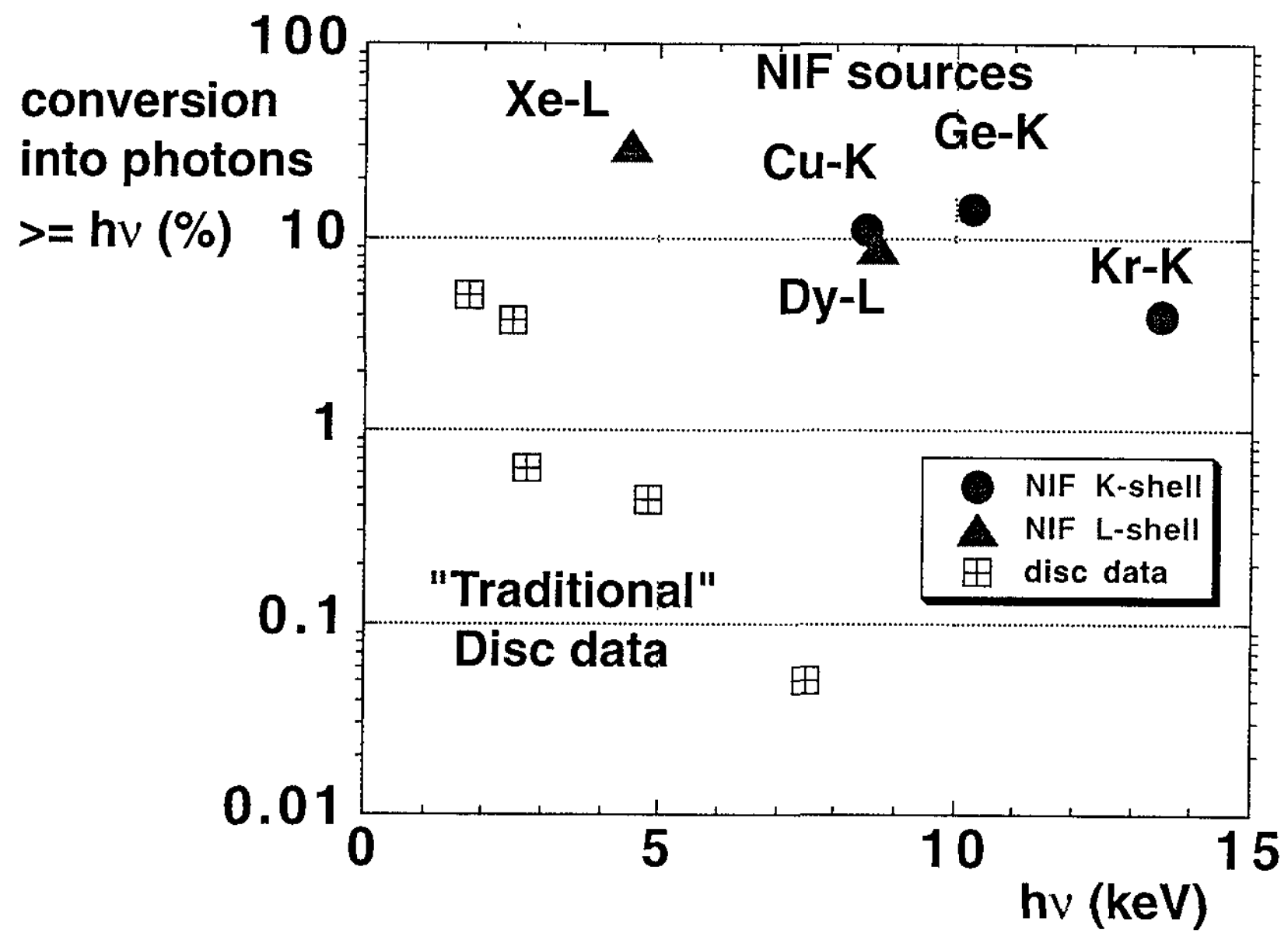

Figure 1- Theory and modeling, supported by experiment, indicates that NIF will be able to convert a very significant fraction of its laser energy into mult-kilovolt radiation using "underdense radiators". The efficiencies are very much greater than from a traditional disc. 

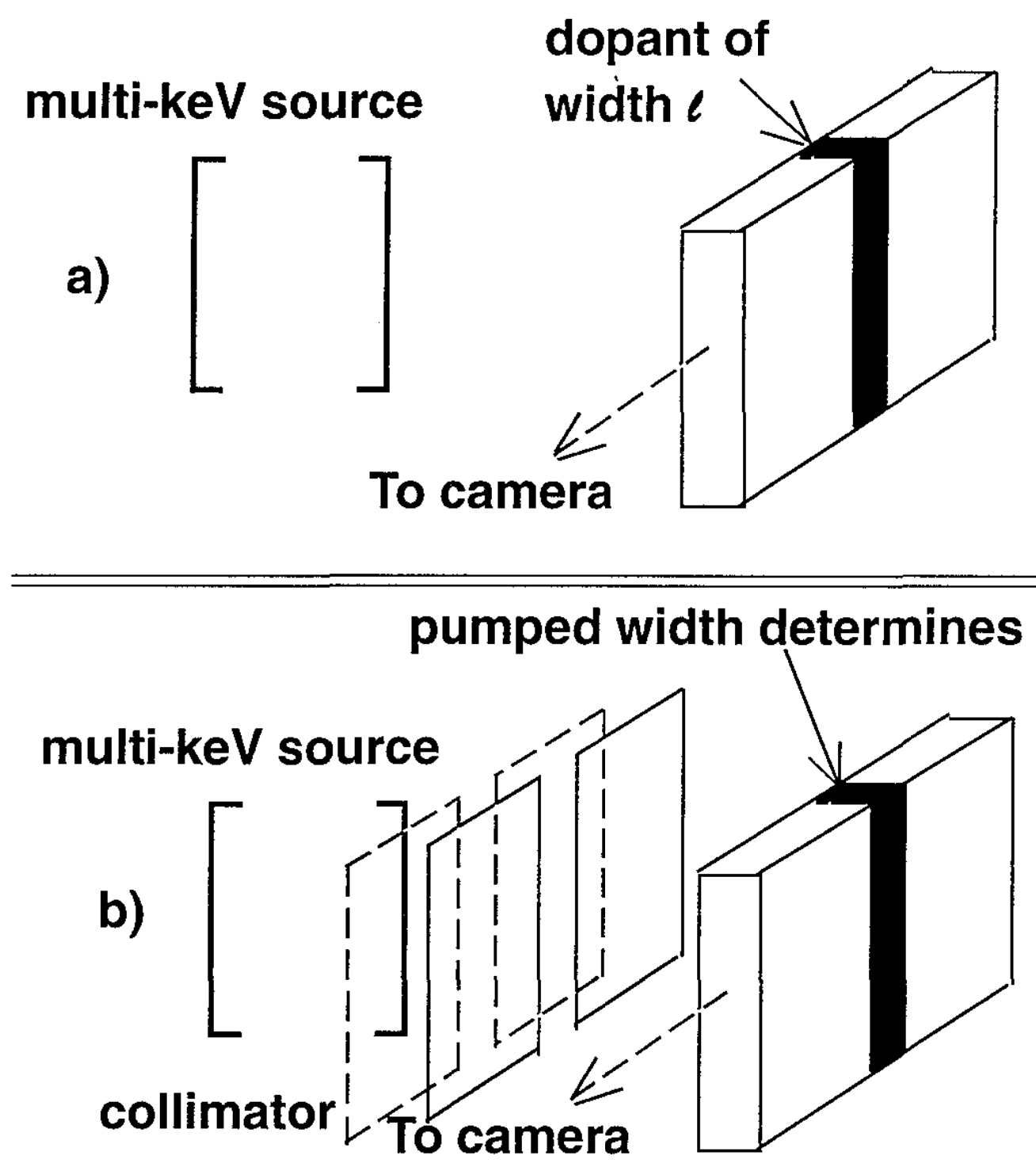

Figure 2- Two approaches for causing only in a "slice" thru the experimental package to fluoresce. 


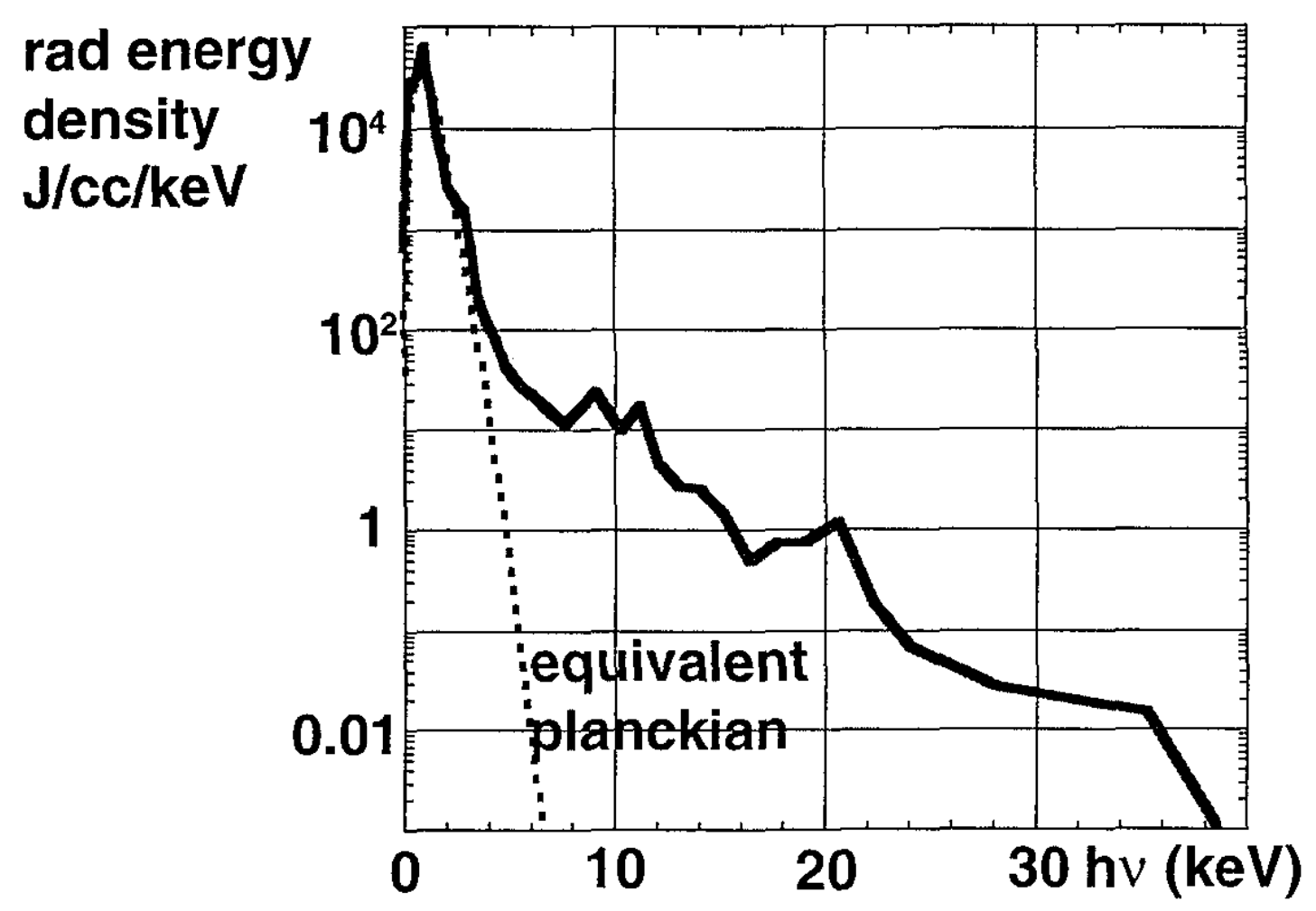

Figure 3- Average radiation field inside a simulated scale 1.0 Nova hohlraum, at $1 \mathrm{~ns}$, when the hohlraum temperature is $-230 \mathrm{eV}$. The hot corona emission from near the LEH causes the high energy radiation field to be $>$ the equivalent planckian which describes the spectrally integrated radiation energy density (J/cc). 


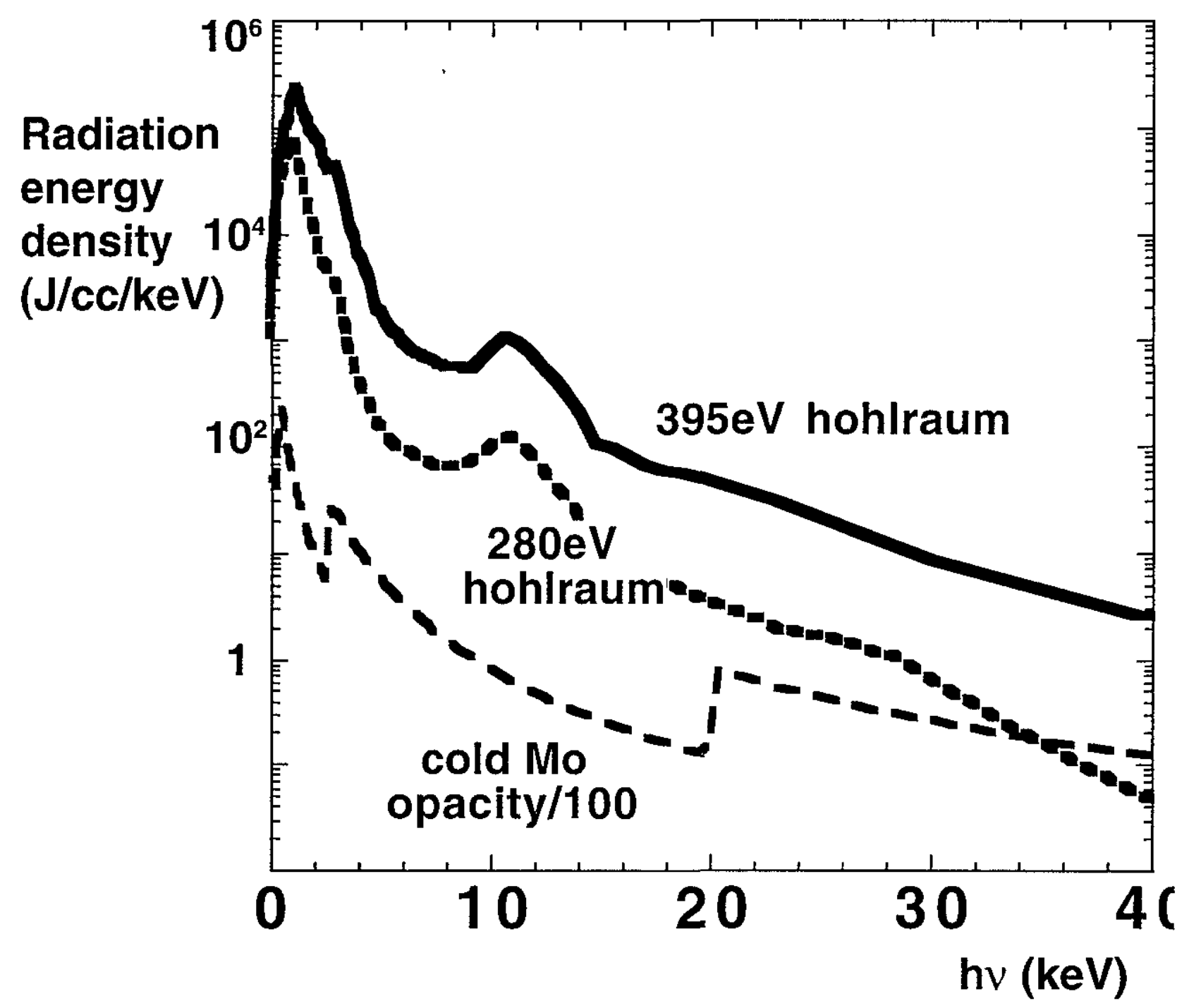

Figure 4- Estimated radiation energy density near the center of a $280 \mathrm{eV}$ and a $395 \mathrm{eV}$ Nova hohlraum. Also shown is the opacity of cold Mo (/100) which has a K-line at $17.4 \mathrm{keV}$ with $47 \%$ fluorescent yield due to radiation absorbed above the $20 \mathrm{keV} \mathrm{K}$-edge. 


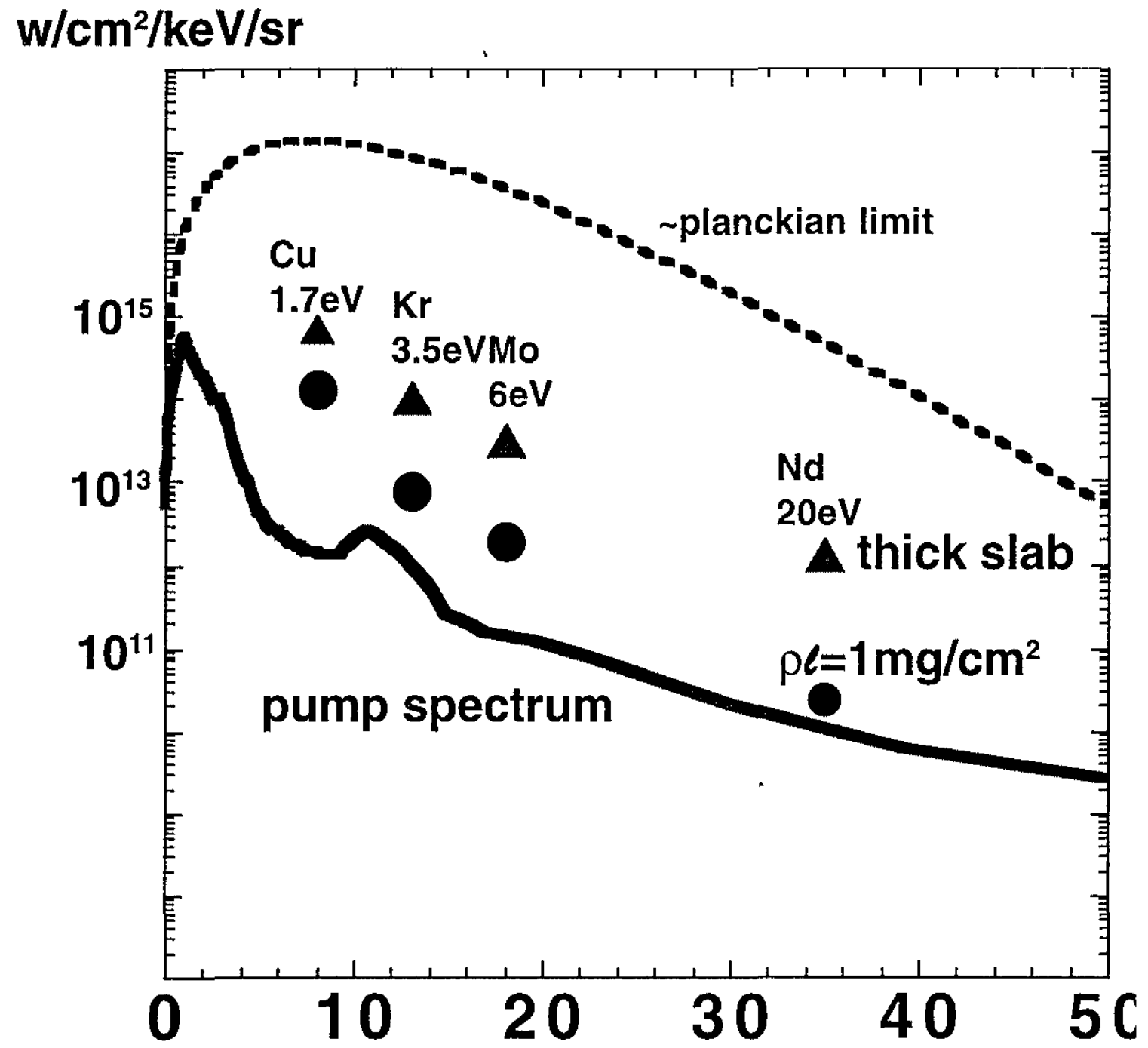

Figure 5- Filled triangles are fluorescent line intensities we expect from thick slabs of material pumped by a $395 \mathrm{eV}$ hohlraum's spectrum. Dots are fluorescent line intensities from a dopant layer of $\rho l=1 \mathrm{mg} / \mathrm{cm}^{2}$. 


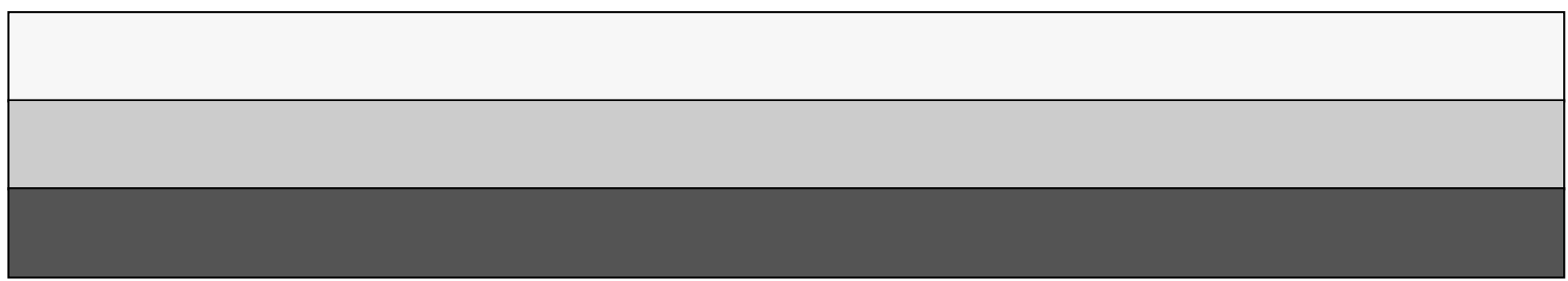

